\title{
Uma escola atraente é um convite para estudar: Erasmo Pilotto e a educação paranaense na década de 1950
}

\author{
Márcia Marlene Stentzler ${ }^{1}$ and Cláudia Sena Lioti ${ }^{1}$ \\ ${ }^{1}$ Ensino \& Pesquisa
}

July 6, 2020

Resumo: Neste artigo abordamos aspectos da história da Educação do Paraná a partir de Erasmo Pilotto, que protagonizou mudanças na educação e formação de professores na década de 1950. Sua vida se entretece ao processo de transformações socioeducacionais, no contexto de implantação da Escola Nova. Objetivamos compreender aspectos de seu pensamento e ação pedagógica a partir do capital sociocultural acumulado. Tendo por base escritos de Erasmo Pilotto, Bourdieu (1998, 2007); Le Goff (2003); Silva (2009, 2014) e Miceli (2007), entre outros. A pesquisa possibilitou conhecer particularidades do pensamento de Erasmo Pilotto, a inserção de suas ideias na educação paranaense e a relevância do capital sociocultural em sua trajetória profissional e pessoal.

Palavras-chave: Educação paranaense, capital sociocultural, transformações socioeducacionais, Escola Nova.

\section{An attractive school is an invitation to study: Erasmo Pilotto and paranaense education in the 1950s}

\begin{abstract}
In this article we approach aspects of the history of Education in Paraná from Erasmo Pilotto, who led changes in teacher education and training in the 1950s. His life is interwoven with the process of socioeducational transformations, in the context of the implementation of Escola Nova. We aim to understand aspects of his thinking and pedagogical action, from the accumulated sociocultural capital. Based on the writings of Erasmo Pilotto, Bourdieu (1998, 2007); Le Goff (2003); Silva (2009, 2014) and Miceli (2007), among others. The research made it possible to know the particularities of Erasmo Pilotto's thinking the insertion of his ideas in education in Paraná and the relevance of sociocultural capital in his professional and personal trajectory.
\end{abstract}

Key-words: Paraná education, sociocultural capital, socio-educational transformations, New School.

\section{Introdução}

Na primeira década do século XX nascia o intelectual paranaense Erasmo Pilotto. Este educador deixou várias contribuições ao ensino para o Estado do Paraná, principalmente no que se refere à expansão do ensino primário e a formação de professores normalistas. Seu legado intelectual é acessível por meio de sua produção nos dias atuais. Suas ideias e bens simbólicos, compreendidos com base em Bourdieu (2007), foram materializados por meio de várias obras escritas, revelando componentes culturais e representações acerca da sociedade e da educação. Ser professor, embora não tenha sido sua primeira escolha no tocante à formação 
profissional, quando jovem, torna-se o esteio de sua vida e produção intelectual na medida em que assume cargos públicos no Estado do Paraná.

Erasmo Pilotto fez parte do grupo de intelectuais que trabalhou em prol de uma escola pública unificada, laica e ativa no Estado do Paraná. À luz dos princípios da Escola Nova[1] e experiências exitosas em outros Estados, como por exemplo Rio de Janeiro, São Paulo e Bahia, num momento histórico em que o discurso governamental era pela modernização e democratização, a educação era a ponte para alcançar esses resultados, conforme demonstram pesquisas de Miguel (1994), Vieira e Marach (2007), Silva (2009, 2014) e Monteiro (2015), entre outras.

Neste artigo, resgatamos aspectos da trajetória deste intelectual, desde o seu nascimento até os anos 1951, quando assume o cargo de secretário de educação do Estado do Paraná, num período em que o país vivia democraticamente e no qual propostas educacionais associadas à Escola Nova estavam sendo implantadas. Concordamos com Bourdieu (2007, p.7) quando escreve que a "posição de um indivíduo ou de um grupo na estrutura social não pode jamais ser definida apenas de um ponto de vista estritamente estático [...] num dado momento [...] o ponto da trajetória que um corte sincrônico apreende, contém sempre o sentido do trajeto social", considerando as influências histórico-sociais e representações construídas sobre ele, incluindo as familiares.

Por meio deste artigo, objetivamos compreender aspectos de seu pensamento e ação pedagógica a partir do capital sociocultural acumulado. Investigamos também as origens e vivências que perpassaram a prática deste educador, cujo trabalho se entretece ao percurso histórico e educacional do Estado, até meados do século XX. Analisaremos, particularmente, o capital sociocultural agregado à sua trajetória via Escola Nova. Buscamos compreender aspectos históricos de sua vida, sua educação familiar e escolar. Esses aspectos pessoais, por vezes desconsiderados em pesquisas, permitem conhecer o que Bloch (2001, p.44) denominava de "espetáculo das atividades humanas", objeto específico da ciência histórica que "é, mais do que outro, feito para seduzir a imaginação dos homens". A história trabalha com indícios, com fontes, logo, as aproximações com os sujeitos são definidas pelas fontes de pesquisa.

Erasmo Pilotto nos deixou seu legado em forma de uma extensa produção intelectual. Utilizamos algumas de suas obras para compor a releitura de sua trajetória, além do livro intitulado: Erasmo - um educador de alma romântica, escrito pela esposa, Anita Pilotto (1987). A forma amorosa que ela o descreve traz representações sobre sua vida, revela memórias e produções dessa natureza que "conservam certas informações" a ser comunicadas a outros, conforme assevera Le Goff (2003, p.419). Por conseguinte, "tornar-se senhores da memória e do esquecimento é uma das grandes preocupações das classes, dos grupos, dos indivíduos que dominaram ou dominam as sociedades históricas". (LE GOFF, 2003, p.422). Os silêncios ou lembranças da história revelam esses mecanismos.

A partir de fontes secundárias e base teórica, buscamos o entendimento sobre sua trajetória condicionada a um sistema simbólico, derivado das condições sociais e relações que se estabeleceram, de acordo com Miceli (2007), sob formas, circunstâncias e num tempo histórico específico.

Assim, abordamos os primeiros anos de sua vida e sua opção pelo magistério, evidenciando contribuições como escritor, professor, diretor, assistente técnico, político e crítico de arte, bem como a sua participação no Movimento Nova Escola e na história da educação do Paraná. O protagonismo e a amorosidade pela educação serão analisadas a partir de Bourdieu (1998; 2007) e Le Goff (2003) no que tange à produção da memória.

\section{As primeiras décadas do Século XX no Paraná}

O final da primeira década do século XX marcou o sul do Paraná e norte de Santa Catarina pela conclusão da ferrovia2 que ligava São Paulo ao Rio Grande do Sul. Os estados do Paraná e Santa Catarina viviam um clima conflituoso, de disputa territorial e, no ano de 1910, o Estado do Paraná perdia, novamente, recurso e embargo judicial para Santa Catarina quanto a posse do território do Contestado. O 
clima de conflito se acirrava, culminando na Guerra do Contestado, entre 1912 e pelo menos 1916, envolvendo sertanejos, forças governamentais e milicianos, entre outros. (STENTZLER, 2015).

Na região sul do Paraná, numa localidade hoje pertencente ao município de Rebouças, nascia Erasmo Pilotto, no ano 1910, (SILVA, 2009). Naquela região, o trem já trafegava há pelo menos 5 anos. A ferrovia simbolizava o progresso e a modernização para as cidades e populações do interior do Estado do Paraná.

A República brasileira, proclamada há pouco mais de uma década, clamava por grandes transformações políticas, econômicas e sociais. Mas, a educação era uma das grandes questões a serem encaminhadas. Era necessário investir para a alfabetização e a formação de professores qualificados, via escola normal. Um grande número de cadeiras criadas não contava com professores. Por isso, o desafio era "dotar de verba orçamentária a Instrução Pública com a quantia suficiente para fazer face às despesas respectivas", com o intuito de preencher as cadeiras criadas. (XAVIER, 1911, p.15). O Relatório da Instrução Pública de 1910 mostrava que havia 514 cadeiras primárias. Contudo, somente 288 estavam providas: 81 para o sexo masculino, 38 para o feminino e 180 promíscuas (mistas). Somavam-se a essas, "129 escolas particulares, subvencionadas pelo governo" (XAVIER, 1910, p.64), entre elas as escolas étnicas. Entretanto, um dos entraves para suprir as cadeiras vagas era a falta de professores brasileiros formados.

A população paranaense era marcada pela multiculturalidade e pela diversidade de povos. Lazier (2003) explica a diversidade étnica com: europeus, asiáticos, africanos e as raízes com ancestrais americanos. "A partir de 1930, o Norte, o Oeste e o Sudoeste do Paraná foram ocupados por migrantes de São Paulo, Minas Gerais, Rio Grande do Sul, Santa Catarina e nordestinos. " (LAZIER, 2003, p.89). As línguas e costumes influenciaram fortemente a organização educacional paranaense nesse período. Segundo Miceli (2007, p. XXV), e consideradas as especificidades da pesquisa, o "caráter arbitrário dos fenômenos e processos sociais" resultam de "uma opção, de uma escolha que cada sociedade realiza em face de um estoque ou matriz ampla de modalidades possíveis", interdependente às relações sociais e organização do estado.

Ainda, de acordo com Huss (2012, p 216), gradativamente "[... os imigrantes europeus assumiram o processo de colonização e tornaram-se proprietários de terras em várias regiões do Paraná". Esse "[...] personagem típico da população paranaense criou a agricultura de abastecimento, a pequena propriedade e participou da economia", segundo a pesquisa de Prosser (2004, p. 40). Com a chegada dos imigrantes, surgem novas demandas educacionais para o estado e diálogos culturais se estabelecem.

A família de Erasmo Pilotto, especialmente por parte materna (família Gonçalves da Motta), era de origem Italiana e, de acordo com Silva (2009, p.339):

[...] seus primeiros representantes brasileiros estiveram ligados à ferrovia; a segunda geração da família, da qual fazem parte Erasmo e seus primos Osvaldo e Valfrido Pilotto, estiveram ligados ao magistério. Todos frequentaram o curso normal em Curitiba e estiveram ligados a instituições e grupos dedicados à educação e à cultura. A família Gonçalves da Motta, por sua vez, era considerada uma tradicional família de comerciantes na cidade de Guarapuava. A mãe e as tias de Erasmo também frequentaram o curso normal em Curitiba.

Erasmo Pilotto nasceu em uma família com formação sociocultural diferenciada. Os bens culturais herdados da família, assim como as influências socioculturais externas, provenientes das relações pessoais, podem ter contribuído para as escolhas que ele realizou quanto ao seu futuro no magistério paranaense. Para Bourdieu (1998), cada indivíduo pode ser caracterizado por uma "bagagem socialmente herdada", perpassando o âmbito econômico, constituído pelo acesso aos bens e serviços; o capital social, caracterizado pelo grupo com quem mantém convívio e relações sociais influentes a partir da família e o capital cultural, caracterizado pela formação escolar e cultural. Esta rede durável de relações exige do indivíduo um esforço até que esteja estabelecida, porém, no decorrer do tempo, proporciona lucros materiais e simbólicos. (BOURDIEU, 1998). 
A mãe de Erasmo era professora[2] primária e seu pai um telegrafista, que faleceu antes do filho completar dois anos de idade. Erasmo Pilotto cresceu sob os cuidados da mãe e de alguns parentes maternos. Embora tenha convivido pouco com o pai, na Autobiografia afirma que o pai foi um grande influenciador da sua formação intelectual, pois em vida era um leitor voraz e lhe deixou uma biblioteca[3] com volumes importantes (a qual foi ampliado com o passar dos anos), fato que o influenciou no gosto pelos estudos e na busca por conhecimento. No entanto, sua mãe foi a pessoa a quem ele atribuiu papel fundamental em sua formação, ela era professora normalista e lhe ensinou o comprometimento com os estudos, buscando as melhores escolas e os meios que mais proporcionassem o seu desenvolvimento. (SANTOS, 2004).

Conforme Monteiro (2015), alguns anos após o falecimento de seu pai, Erasmo Pilotto mudou-se com a mãe e os avós maternos para a capital do estado, Curitiba, onde fez o curso primário no Grupo Escolar Xavier da Silva, de 1917 a 1921. Estudou também no colégio particular Teodorico Guimarães, "como ainda não tinha idade para ingressar no Ginásio, foi matriculado lá para se preparar para o exame de admissão " (MONTEIRO, 2015, p.30). Essas oportunidades de escolarização revelam o compromisso da mãe com a educação de Erasmo Pilotto e, possivelmente, o amor deste educador pelo ensino tenha raízes em sua infância, por meio da biblioteca que o pai deixou (como portas abertas para o mundo), das descobertas da educação escolar e das vivências familiares e sociais. Tantas oportunidades foram provavelmente transformando sua vida...

Após prestar exame de admissão, Erasmo Pilotto foi aprovado para cursar o ensino secundário no Ginásio Paranaense, em Curitiba, (MONTEIRO, 2015). Segundo Oliveira (2001), esta escola era, juntamente com a Escola Normal e o Curso Mercantil, os estabelecimentos públicos de ensino secundário da cidade de Curitiba. Concluída a fase ginasial, mudou-se para o Rio de Janeiro, onde almejava estudar Engenharia. Contudo, a Escola Politécnica mudou as exigências para o ingresso e passou a exigir a fluência em latim para os ingressantes no curso, até então necessária apenas para os cursos de Direito. Com isso, retornou a Curitiba e iniciou sua carreira no magistério, na qual traria importantes contribuições e transformações para a educação do Estado do Paraná.

Sobre sua trajetória formativa na escola normal, há registros de que em 1927/1928 estava matriculado na Escola Normal de Curitiba, sendo que, no ano de 1928 estava registrado na turma do $4^{\mathrm{O}}$ ano da referida escola, conforme mostra o Relatório. (RELATÓRIO da Instrução Pública do Paraná, 1928, p. 48). Erasmo Pilotto exerceu forte influência no campo artístico e intelectual. Em 1927, quando cursava o ensino Normal, fundou o Centro de Cultura Filosófica, "grupo interessado em debater a modernização das artes e da literatura em Curitiba". (SILVA, 2014, p.14).

Ele atuou na fundação da Sociedade de Cultura Artística Brasílio Itiberê (SCABI), que com o auxílio de um grupo de artistas e intelectuais associados à fundação, organizou diversos concertos musicais no município de Curitiba. Participou também da criação do Salão Paranaense de Belas Artes e da fundação da Escola de Música e Belas Artes do Paraná (Embap). Além disso, publicou ensaios sobre artistas e escritores paranaenses por meio do jornal Diário da Tarde e O Dia, além crônicas e críticas de arte (SILVA, 2014).

\section{Erasmo Pilotto: uma trajetória pela educação}

De acordo com Silva (2009; 2014), em 1929, após concluir seus estudos na Escola Normal de Curitiba e, em razão das relações estabelecidas com o campo político, por meio de estreitamentos familiares, Pilotto foi convidado a lecionar a disciplina de português na Escola Normal de Paranaguá. Essas relações sociais, as quais Bourdieu (1998, p.67), denominou "capital social", são resultado de uma construção histórica, provavelmente atrelada à "bagagem socialmente herdada" que permeou as decisões, as escolhas e indicações para os cargos que viria a ocupar como diretor das escolas normais primárias em Ponta Grossa e Paranaguá. Esses fatos reafirmam o impacto do capital sociocultural herdado da família e também construído a partir das relações sociais.

Em 1933 casou-se com Anita Camargo e no mesmo ano foi aprovado em um concurso para a cadeira de 
Pedagogia na Escola Normal Secundária de Curitiba. Assumiu no ano seguinte a regência das cadeiras de Psicologia, Biológica Aplicada à Educação e História da Educação na mesma instituição. Isso lhe garantiu uma posição de autoridade no campo educacional, ao realizar ações que tornaram a Escola de Professores um centro de cultura, com concertos, exposições e mostras, sob a perspectiva de que a arte era fundamental na formação de professores, (SILVA, 2014). Haja vista que revela a sensibilidade artístico-cultural e a compreensão da educação como um processo complexo, composto por diferentes áreas do conhecimento.

Atuando em conjunto com outros intelectuais paranaenses, Erasmo Pilotto já estava envolvido com a introdução e disseminação das ideias de renovação da educação e implantação dos princípios educativos da Escola Nova, no Estado do Paraná. Em sua autobiografia, ele argumenta: "não fui diretamente o mestre de meninos, ou mestre da escola, mas toda a minha vida foi um sincero serviço, sem interrupção de um dia, à causa da educação". (SANTOS, 2004, pp. 26-27). O percurso educacional e profissional de Erasmo Pilotto revela sua origem na classe média paranaense, no entanto ele avançou de forma significativa nesse percurso, se comparado com a formação adquirida ao longo da vida por seus genitores e também quanto a acumulação de capital cultural, de uma sólida rede de relações sociais e representações construídas acerca de sua pessoa e profissão.

Em Erasmo: um educador de alma romântica, obra escrita por Anita Camargo Pilotto (1987), a autora descreve suas atitudes profissionais por meio de anotações extraídas de seu diário. No entendimento da autora, Erasmo era possuidor de uma alma romântica. (PILOTTO, 1987). A amorosidade de sua esposa também revelava seu capital sociocultural e os seus bens simbólicos, nesta perspectiva, atribuímos à Erasmo Pilotto preocupação com uma verdadeira transformação social por meio da educação.

Enquanto trabalhava no Instituto de Educação de Curitiba (nova denominação para a Escola Normal Secundária) (1937-1948), orientava e incentivava os professores para práticas vivas e envolventes. (SILVA, 2014). Naquele período, ele atuava como diretor técnico e criou o jornal A voz da escola; "um órgão da associação de alunos daquele instituto", escreveu Pilotto na obra específica sobre o Estado do Paraná da série de monografias sobre os sistemas estaduais de educação, segundo relatório publicado por MEC, INEP e CILEME (1954, p.39). O jornal também divulgava resultados de pesquisas feitas com estudantes, como por exemplo as que foram publicadas em 1941, sobre a estatura de meninos e meninas de diferentes idades. Era uma forma de envolver os alunos e despertar a consciência sobre realidade educacional e social.

Ele "acreditava que a relação entre o educando e o educador deveria ser viva, que não poderia ser fechada dentro de nenhum tecnicismo, de nenhum processo fixo, objetivando a busca pelo novo em todos os momentos", como destacam Monteiro e Schelbauer (2015, p. 3-4). Em 1943, com a criação do Instituto Pestalozzi, ele organizava um espaço para colocar em prática uma educação com base nos ideais escolanovistas. Erasmo desejava que as "crianças pudessem aí viver como se estivessem em um lar concebido expressamente para elas [...] usando livremente o que aí encontrasse [...]", conforme sistematizou no livro Prática de Escola Serena. (PILOTTO, 1946, p. 16). Ao professor Erasmo, incomodava o fato do elevado número de reprovações escolares, conforme MEC, INEP e CILEME (1954, p.73):

[...] só uma bem reduzida parte da população escolar que iniciou o curso primário o conclui, diminuindo, sensivelmente, o número de alunos na medida em que nos aproximamos dos últimos anos primários, verificase a conclusão inafastável de que, mesmo do número de alunos que acorrem à escola, apenas uma porção bastante reduzida chega a ter mesmo um aproveitamento de grau primário.

Ele entendia que as práticas educacionais necessitavam mudar e isso deveria perpassar pela formação de professores, especialmente por meio das Escolas Normais, estas, assumindo as salas de aula, teriam condições efetivas de trabalhar com novas propostas educativas, pois as reprovações também tinham um elevado custo financeiro para o Estado. Segundo Silva (2014), seus diálogos e parcerias com outros professores, como Raul Rodrigues Gomes resultou na fundação do Grupo Editorial Renascimento do Paraná (GERPA), no ano de 
1944. Dois anos após, ele contribuía com Dalton Trevisan para fundar a revista Joaquim. De acordo com Romanovski (2008), a proposta dessa revista era clara. Tratava-se de "uma oposição explícita às tradições paranaenses que, comumente agrupadas no rótulo de "paranismo", instituíram uma forma de se pensar o Paraná enquanto progressista e moderno"(ROMANOVSKI, 2008, p.7).

O Instituto Pestalozzi foi uma escola pré-primária particular, criada por Pilotto em 1943, "paralelamente à atuação na Escola de Professores" (SILVA, 2014, p. 340), onde desenvolvia seu projeto educativo. "Pilotto desenvolveu uma teoria educativa baseada na formação de uma cultura artística para os professores, por ele sintetizada na frase 'eduquem-se em arte'" (SILVA, 2014, p. 340). A proposta pedagógica difundida por meio do Instituto Pestalozzi e na Escola de Professores era altamente desejada para a educação. Possuidor de capital cultural e social reconhecido e respeitado, ele foi convidado a assumir o cargo de Secretário de Educação e da Cultura do Estado Paraná, entre 1949 e 1951, no governo de Moysés Lupion. Nesse ínterim, buscava-se a ampliação das escolas normais e metodologias modernas para a educação, especialmente para as áreas rurais, onde havia defasagem. Para essas escolas, segundo Silva (2014, p.347),

A orientação seguiria algumas áreas traçadas inicialmente por Pilotto, as quais compreenderiam as seguintes atividades: orientação geral, ensino de leitura e aritmética, atividade social da escola, decoração escolar, atividade agrícola e pecuária, recreação, teatro, folclore, pintura ao ar livre, modelagem, educação sanitária rural, educação física, geografia e ciências naturais.

À frente da secretaria de educação do Estado do Paraná, Erasmo Pilotto criou os Cursos Normais Regionais no interior do Estado, uma forma de tentar estender a possibilidade de escolarização àqueles que viviam longe dos grandes centros, respeitando as especificidades das áreas rurais e ofertando instrução primária a todos. Ele desenvolveu programas experimentais que dedicavam grande parte do currículo ao ensino de arte, transformou a escola secundária, tornando-a obrigatória e gratuita. Conforme os estudos de Miguel (1994), por meio das intervenções de Erasmo Pilotto, foi eliminada a necessidade do exame de admissão, fazendo com que o ensino secundário se tonasse uma sequência da escola primária, porém, distribuindo a clientela "por vários tipos de escolas". Nessas escolas deveria existir a "iniciativa local e experiências", refletindo as tradições sociais e as atmosferas morais", bem como "as condições econômicas das diferentes localidades"(PILOTTO, 1952, p.91).

Enquanto secretário de educação visitou várias escolas em todo o Paraná, inclusive as escolas isoladas no interior do Estado, ouvindo e orientando os professores. Os registros destas experiências estão em seu livro Educação é direito de todos, (PILOTTO, 1952). Criou, juntamente com um grupo de professores, a Associação Paranaense de Estudos Pedagógicos na qual realizou pesquisas educacionais em diversas áreas. Algumas destas pesquisas podem ser encontradas na Revista de Pedagogia, publicadas por esta mesma Associação (SILVA, 2014).

Segundo o estudo realizado por Miguel (1994), após deixar o cargo de Secretário de Educação do Paraná, em 1951, Erasmo seguiu trabalhando em prol da educação, "exercendo permanentemente a prática pedagógica independente do cargo que ocupava" (MIGUEL, 1994, p. 1). Em vida, recebeu alguns prêmios, como Honoris Causa da Universidade Federal do Paraná, em 1982, uma prova de que a motivação individual que movia o seu trabalho sempre foi reconhecida e valorizada. Anita relata que o lema de Erasmo Pilotto era "Educar os futuros educadores" e que seus gestos, palavras e ações, eram, por si, educativos (PILOTTO, 1987).

Vieira e Marach (2007, p. 270) analisam as atitudes engajadas de intelectuais como Pilotto, essas, "incorporam sentimento de missão social, inserindo-se na cena pública como guias do povo". Erasmo Pilotto sistematizou sua concepção educacional por meio de publicações[4] diversas. Ele possui uma vasta produção como gestor de políticas públicas educacionais, especificamente como relator de experiências para conduzir o trabalho de professores de escolas primárias e de educação infantil. 


\section{O movimento escola nova na vida e obra desse intelectual}

Erasmo Pilotto lutou pela inserção das ideias da Escola Nova no Paraná, assim como em outros estados e em âmbito nacional, Fernando Azevedo (1894-1974), Lourenço Filho (1897-1970), Anísio Teixeira (19001971) e outros representam a busca por transformações curriculares na educação, tendo por base os ideais do escolanovismo. Segundo Vieira e Marach (2007, p. 270), estes educadores são "um exemplo sem precedentes na história brasileira do poder de mobilização da causa educacional na formação de um grupo de intelectuais sofisticados e, sobretudo, influentes na sociedade brasileira". Consideradas as especificidades da pesquisa, as representações acerca da educação e concepções teóricas podem ser compreendidas a partir de condições sociais favoráveis "à separação e divisão do trabalho simbólico", uma vez que a "atividade teórica, repousa, portanto, no privilégio" de ser lugar para compreender determinações, fatos simbólicos que correspondam à realidade, (MICELI, 2007, p. XXXVII).

O trabalho intelectual de Pilotto possibilitou a materialização de novas práticas educativas. Essa produção existiu em função de condições sociais determinadas e de profissionais especializados, estabelecendo novos parâmetros e organização à prática educativa. De acordo com Bourdieu (1998), em sua obra Sociologia da educação, é necessário romper com a ideologia do dom e a noção moralmente carregada de mérito pessoal, em que se passa a analisar as vantagens sociais como advindas das relações familiares e não como fruto dos diferentes caminhos percorridos ou das diferenças naturais entre os indivíduos. Erasmo Pilotto desenvolveu uma proposta educativa considerando as singularidades e generalidades das populações paranaenses, em particular das áreas rurais.

O "grande movimento" teórico5 da Escola Nova (PILOTTO apud VIEIRA, 2007 p.61), que atraiu Erasmo Pilotto para a renovação da educação, tinha como ideal a ação, os fatos e as coisas para a transformação social. O protagonismo e o engajamento eram centrais para a transformação do indivíduo e da sociedade, como parte de um complexo processo, passando, particularmente, pela alfabetização. Conforme o relatório de Pilotto sobre o Estado do Paraná, publicado por MEC, INEP e CILEME (1954, p.118), "a criança só pode ser conhecida, integrada na compreensão do complexo, da orgânica familiar e a educação escolar; frequentemente, só se poderá aspirar a educar a criança educando o complexo familiar. " Dessa forma, a educação deveria se iniciar pela criança, cabendo aos adultos que a cercam, educá-la.

A família ocupava papel central para a educação da criança na concepção de Pilotto, como a força necessária para alcançar os objetivos educacionais. Na medida em que a criança cresce e avança em sua escolarização, novas necessidades emergem. Ainda, conforme o relatório MEC, INEP e CILEME (1954, p.119) apontava que somente a metade das crianças até 15 anos estavam alfabetizadas, implicando em dificuldades para os outros níveis de escolarização, como a escola profissional, por exemplo. Os professores deveriam ser formados para a

[...] pedagogia de uma escola primária completa, de recuperação, dentro das exigências bio-psicológicas de idade. E tal escola deve ter, em geral, um caráter transitório, pois que, na verdade, em geral, não deve de futuro ocorrer que chegue aos 12 anos, analfabetos, $50 \%$ de nossa população. É uma escola, em verdade, para uma emergência. (MEC; INEP; CILEME, 1954, p.121)

No movimento Escola Nova, a preocupação não estava voltada apenas às questões relacionadas à metodologia de ensino, ou à ação do mestre, o objetivo era de que os indivíduos que formavam o corpo escolar, assim como a sociedade em geral, passassem a atribuir uma nova significação à escola, integrando-a ao meio social e físico. Essas mudanças podem ser compreendidas tendo como referência John Dewey (1979), para quem a escola, a própria vida é um local de preparação para ela. E, Erasmo Pilotto buscava para o Paraná uma educação em que o eixo norteador passasse pela experiência e a aprendizagem.

A "Escola Nova deve se dar pela ação e não pela instrução. Para ele, essa concepção tem que ser uma experiência concreta, ativa e produtiva em cada um". (GADOTTI, 1996, p. 143). Em sua ação como inte- 
lectual e educador, Erasmo Pilotto analisou a si próprio e ponderou: "procurei dar pequenos passos, sempre em respeito a direitos fundamentais do homem, que nasceram de uma consciência dolorosa de gravíssimos problemas daquele organismo de administração do Estado" (PILOTTO, 1952, p.5). Seu desejo de alcançar uma educação humanizadora pode ser assim sistematizada:

Problemas materiais dos homens são vivíssimos, mas, se virmos bem, todos os problemas dos homens estão ligados a problemas da ideia e da vontade, da construção interior, e sem solver a estes não adiantam os mil projetos mais bem-sucedidos que têm em vista a vida material. (PILOTTO, 1973, p.146).

Notamos que na medida em que reconhece novas possibilidades para o fazer educativo, respeitando e se preocupando com as diferenças que possam interferir no processo educacional, para Puglielli [et al.] (1996, p.5), enquanto "A maioria dos pedagogos e das pedagogias se ocupa da escola. Erasmo Pilotto se preocupou com o homem". Ainda, segundo Miguel (1997, p.109), ele buscou encontrar naqueles que lhe serviram de modelo, melhores formas de realizar a educação pública.

Ao longo de sua vida, ele deixou evidente seu compromisso com a educação como um processo complexo, envolvendo experiências, sentimentos, sensações e percepções. Pilloto tinha compreensão da complexidade do ato educacional e da necessidade de transformar a educação de seu tempo. Preocupava-se, especialmente, com relação à formação e ao trabalho dos professores de áreas rurais onde, raramente, os formados na escola normal aceitavam lecionar:

É necessário que nós nos coloquemos em um novo ponto de vista em relação à função da escola primária e aos trabalhos do mestre. De início, é necessário compreender que um programa escolar não pode ser um mero registro de matérias a ensinar. É um plano de trabalho, e a função do mestre não pode ser um mero registro de matérias e ensinar. É um plano de trabalho, e a função do mestre não pode estar limitada à função elementar da ministração de conhecimentos. (PILOTTO, 1946, p. 46)

Para o autor, a educação era compreendida como um processo complexo, o ato de educar exigia conhecimento e amor. O trabalho do professor deveria ser abrangente, agir para a transformação da sociedade paranaense. Consideramos que a educação, como um "campo simbólico", se organiza como parte de um "conjunto de aparelhos mais ou menos institucionalizados de produção de bens culturais" e, para se efetivar, "tem que levar em consideração os corpos de agentes altamente especializados na produção e difusão desses bens" (MICELI, 2007, p.LIII). O capital sociocultural de Erasmo Pilotto possibilitou propor ações para renovar o sistema de ensino por meio da formação, política, crítica, técnica e pedagógica do professorado, tendo como principal alvo as escolas públicas paranaenses.

Erasmo Pilotto faleceu em maio de 1992, na cidade de Curitiba, aos 82 anos. Seus escritos e o estudo de sua trajetória revelam sua sensibilidade quanto à educação. Ele acreditava nas forças transformadoras. Pilloto, tinha a convicção do papel essencial da escola primária na vida das crianças e a complexidade do problema de ofertar aos alunos uma escola que de fato oportunize reais condições de aprendizagem e alfabetização. Para ele, o caminho possível era o de "fazer uma escola atraente e realizar uma profunda mobilização de forças de propaganda", (MEC; INEP; CILEME, 1954, p.121). Um padrão a ser seguido em todas, inclusive como treinamento para os professores, respeitadas as diferenças regionais.

\section{Considerações finais}

Conhecer a história da educação é ter argumentos e elementos para repensar as práticas educativas no tempo presente. O caminho percorrido por Erasmo Pilotto na educação paranaense revela um homem sensível aos 
problemas de seu tempo e a educação como um mecanismo para a superação de problemas. Contudo, mudanças educacionais passariam por uma nova concepção na formação da infância e da juventude paranaense e estudos dessa natureza eram deficientes. Em poucos anos, Pilotto conseguiu publicar inúmeros livros e materiais que possibilitaram conhecer aspectos da realidade socioeducacional do Paraná, bem como possibilidades para a ação docente, tendo em vista uma prática comprometida com o conhecimento, mas também com amor pela educação.

Ele tinha convicção de que mudanças seriam possíveis na medida em que houvesse outras ações convergentes e gradativas, como a obrigatoriedade escolar e o financiamento para a educação. Também defendia que se constituísse um sistema orgânico e permanente para a formação de professores nas diferentes modalidades, em nível elementar e médio, sobretudo no campo das práticas pedagógicas, sem improvisos. Sua extensa produção intelectual revela um educador preocupado com os problemas educacionais de seu tempo e potencialidades da educação para o desenvolvimento paranaense.

Na perspectiva bourdieusiana, Erasmo Pilotto superou a expectativa do seu grupo social e alcançou a fração intelectualizada da elite paranaense. Ele foi um agente intelectual e político que, com sensibilidade e espírito científico, logrou importantes renovações e fez parte de uma profunda mudança nos paradigmas da educação do nosso Estado.

\section{Referências}

BLOCH, Marc. Apologia da História ou o ofício do historiador. Rio de Janeiro: Jorge Zahar Editora, 2001.

BOURDIEU, Pierre. Escritos de Educação. Petrópolis: Vozes, 1998.

BOURDIEU, Pierre. A economia das trocas simbólicas. Introdução, organização e seleção Sergio Miceli. São Paulo: Perspectiva, 2007. (Coleção estudos).

DEWEY, John. Experiência e educação. 3.ed. São Paulo: Ed. Nacional, 1979.

GADOTTI, Moacir. História das Ideias Pedagógicas. São Paulo: Ática, 1996.

HUSS, Silvana Rodrigues Malheiro. O processo de escolarização no município de Mandaguari-Pr (1949-1988). Dissertação (Mestrado em Educação). Programa de Pós-graduação em Educação da Universidade Estadual de Maringá. 2012.

LAZIER, Hermógenes. Paraná: Terra de todas as gentes e de muita história. Francisco Beltrão: Grafit-gráfica e Editora Ltda, 2003.

LE GOFF, Jacques. História e Memória. 5. ed. Campinas, SP: UNICAMP, 2003. 
MEC. INEP. CILEME. A educação do Paraná: síntese sobre o ensino público elementar e médio. No.3. Rio de Janeiro, 1954. (Série de monografias sobre os sistemas estaduais de educação).

MICELI, Sergio. Introdução. In: BOURDIEU, Pierre. A economia das trocas simbólicas. Introdução, organização e seleção Sergio Miceli. São Paulo: Perspectiva, 2007. (Coleção estudos).

MIGUEL, Maria Elisabeth, Blanco. A formação do professor e a organização social do trabalho. Curitiba: UFPR, 1997.

MIGUEL, Maria Elisabeth, Blanco. O significado do trabalho de Erasmo Pilotto no cenário educacional paranaense. In: Educar em Revista. n.10. Curitiba: UFPR, 1994.

MONTEIRO, Cicília Rodrigues. Contribuições de Erasmo Pilotto para expansão do ensino primário no Paraná: ensino rural, alfabetização e formação de professores (1940-1970). 91 f. Dissertação (Mestrado em Educação). Programa de Pós-graduação em Educação da Universidade Estadual de Maringá. 2015.

MONTEIRO, Cicília Rodrigues; SCHELBAUER, Analete Regina. Erasmo Pilotto a idealização da escola perfeita: a criação do Instituto Pestalozzi. In: Seminário do PPE. Universidade Estadual de Maringá. Maringá: UEM, 2015.

OLIVEIRA, Maria Cecília Marins. Organização Escolar no início do século XX: o caso do Paraná. In: Educar em Revista. No. I 8. Curitiba: UFPR, 2001. pp. 143-155.

PILOTTO, Anita. Erasmo: um educador de alma romântica. Curitiba: Editora Rocha, 1987.

PILOTTO, Erasmo. Prática de Escola Serena. Curitiba: [s.l.],1946.

PILOTTO, Erasmo. A educação é direito de todos. Curitiba: [s.l.], 1952.

PILOTTO, Erasmo. Obras I. Curitiba: Imprimax, 1973.

PROSSER, Elizabeth Seraphim. Cem anos de sociedade, arte e educação em Curitiba (1853-1953): da Escola de Belas Artes e Indústrias, de Mariano de Lima, à Universidade do Paraná e à Escola de Música e Belas Artes do Paraná. Curitiba: Ed. Assembleia Legislativa do Paraná, 2004.

PUGLIELLI, Helio de Freitas. Erasmo Pilotto. Curitiba: Editora da UFPR, 1996. (Série Paranaenses, n. $7)$. 
RELATÓRIO da Instrução Pública do Paraná, 1928. Disponível em https: //www . arquivopublico. pr.gov.br/arquivos/File/RelatoriosSecretarios/Ano_1928_MFN_1038.pdf . Acesso em: 21 de maio de 2020 .

ROMANOVSKI, Natália. Os moços da província: a Revista Joaquim e o campo literário no Paraná. Monografia. Curso de Ciências Sociais, Setor de Filosofia, Ciências Humanas e Letras, Universidade Federal do Paraná. Curitiba, 2008.

SANTOS, Denise Grein (org). Autobiografia: Erasmo Pilotto. Curitiba, PR: UFPR, 2004.

SILVA, Rossano. A arte como princípio educativo: um estudo sobre o pensamento educacional de Erasmo Pilotto. Dissertação (Mestrado em Educação) - Universidade Federal do Paraná, Curitiba, 2009.

SILVA, Rossano. Educação, Arte e Política: a trajetória intelectual de Erasmo Pilotto. 2014. Tese (Doutorado em Educação) - Universidade Federal do Paraná, Curitiba, 2014.

STENTZLER, Márcia Marlene. Entre questões lindeiras e a superação de fronteiras: a escola complementar em Porto União (SC) e União da Vitória (PR)1928-1928. 2015. Tese (Doutorado em Educação). Programa de Pós-Graduação em Educação da Universidade Federal do Paraná, Curitiba, 2015.

VIEIRA, Carlos Eduardo; MARACH, Caroline Baron. Escola de Mestre único e a escola serena: realidade e idealidade no pensamento de Erasmo Pilotto. In: VIEIRA, Carlos Eduardo (org.). Intelectuais, educação e modernidade no Paraná. Curitiba: UFPR, 2007.

XAVIER, Luiz Antonio. Relatório Apresentado a Exmo. Sr. Francisco Xavier da Silva, Presidente do Estado do Paraná. Curityba: Typ. Da República, 1910. Disponível em:

http://www.arquivopublico.pr.gov.br/arquivos/File/RelatoriosSecretarios/Ano_1910_MFN_743. pdf Acesso em: 17de maio de 2020.

XAVIER, Luiz Antonio. Relatório Apresentado a Exmo. Sr. Francisco Xavier da Silva, Presidente do Estado do Paraná. Curityba: Typ. Da República, 1911. Disponível em: https://www.scielo.br/ scielo.php?script=sci_nlinks\&ref=000111\&pid=S0104-4060200100020000800045\&lng=en Acesso em: 24 de maio de 2020.

[1] O movimento Escola Nova tinha por objetivo voltar a ação pedagógica para a investigação e ação que proporcionassem a autoformação, valorizando a espontaneidade e a iniciativa do indivíduo e propondo uma educação capaz de proporcionar mudanças sociais. Era um movimento crítico à educação tradicional, pois para eles, esta acabava "substituindo a alegria de viver pela inquietude, o regozijo pela gravidade, o movimento espontâneo pela imobilidade, as risadas pelo silêncio". (GADOTTI, 1996, p. 143). 
[2] Segundo Silva (2009), além da mãe, seus primos paternos, Osvaldo e Valfrido Pilotto, também estiveram ligados ao magistério.

[3] Após o falecimento de Erasmo Pilotto, sua biblioteca foi doada à Universidade Federal do Paraná (UFPR). Conforme Miguel (1994, p.1), "No segundo semestre de 1993, a Biblioteca Central da Universidade Federal do Paraná, durante a comemoração da ampliação de suas instalações inaugurou uma placa dourada com o nome do professor Erasmo Pilotto. Esse ato quis objetivar o agradecimento da Universidade à doação das treze mil obras que compunham o acervo particular do mestre paranaense e que hoje pertencem ao patrimônio universitário."

[4] Oração de Paraninfo (1940), Emiliano (1945), Escola Serena (1946), Reorganização do Ensino Secundário (1949), A Educação é Direito de Todos (1952), Temas da Educação de Nosso Tempo: Teologia Pedagógica (1954), A Educação no Paraná: Síntese Sobre o Ensino Elementar e Médio (1954), Problemas Abertos de Sistemas Escolares para o Brasil (1958), Situações do Desenvolvimento Brasileiro e a Educação (1959), Direito à Educação (1960), Prioridades Financeiras para o Ensino Paranaense, Organização e Metodologia para o Ensino Paranaense na $1^{\text {a }}$ Série Primária(1964). Um Caminho para o Aperfeiçoamento da Escola Pública Primária em Países em Desenvolvimento (1964), Graal (1965), Fatos e Expectativas Novos na Educação da América Latina (1965), Problemas da Educação (1966), Livro Que se Exalte um Mestre em Cada Sonho! (1967), Para um Humanismo Individualista (1968), Obras I (1973), Obras II (1976), Informe sobre Treinamento de Mestre e Alfabetização (1980), Mestre de Meninos: Apontamentos para um Discurso (1982), Apontamentos para uma Pedagogia Fundamental (1982). (MONTEIRO, 2015). Além das produções elencadas, há também os trabalhos na área de biografias, de autoria de Erasmo Pilotto como, Emiliano (1945), Theodoro de Bona (1948), João Turin (1953), Dario Velozzo (1969) e Mallarmé: Carta à Colombo de Souza (1982). (MONTEIRO, 2015). 